\title{
SOBRE "JACOB", POEMA DE ALFONSO REYES, ESCRITO EN PARÍS (1925)
}

Jacob

Noche a noche combato con el ángel, y llevo impresas las forzudas manos y hay zonas de dolor por mis costados.

Tiemblo al nacer la noche de la tarde, y entra sed de cuchillo por mis flancos, $y$ ando confuso y temeroso ando.

Quiere correr a consunción mi sangre y aunque sé que en su busca me deshago, otra vez lo persigo y lo reclamo.

Bajo las contorsiones del gigante, aúllo a veces - oh enemigo blancoy dentro de mí mismo estoy cantando.

¡Oh sombra musculosa, oh nube grave! Derrótame una vez para que caiga, o de una vez rómpeme el pecho y ábreme entre los dos reflejos de tu espada.

París, $1925^{1}$

${ }^{1}$ Publicado en La vega $y$ el soto [1946]; también en $A R O C$, t. 10, pp. 113-114. 
Nos sorprendió cierta tendencia en letrados amigos mexicanos, a menudo estudiantes, a veces mayores: celebraban en Alfonso Reyes al ensayista, al humanista, pero apreciaban menos en él al poeta. Sin embargo, como su contemporáneo Jean Cocteau, de obra igualmente variadísima, Reyes se quería, y era, ante todo, poeta: poeta de teatro en Ifigenia cruel; poeta en prosa con Visión de Anáhuac o los deliciosos Cartones de Madrid; poeta conmovedor de su infancia regiomontana y de la familia; poeta elegíaco, del amor, de la amistad... Todos nos acordamos de su entrevista con Robert Escarpit:

-Humaniste! Je me suis classé humaniste parce-qu'il me fallait bien une étiquette.

—Qu'êtes-vous donc, maître?

-Poète, mon cher ami, poète...2

De aquí estas reflexiones a propósito de "Jacob", un poema breve, de relativa y nueva libertad en la disposición de las estrofas, pero clásico en su métrica y rigor. Y eso, en plena explosión surrealista. Confidencia íntima, que su autor mantuvo inédita más de veinte años. Poema fuerte, claroscuro de tres colores sólo, pero cuán profundos y gongorinos: la sangre, el fulgor del cuchillo, un blanco nublado, destacándose en las tinieblas totales. De ruidos intensamente emotivos en su contraste: aullidos y canto. Versos centelleantes de antítesis que se entrecruzan y multiplican como espejos: la noche y lo blanco; el enemigo blanco; la sombra, musculosa; la nube, grave. El gigante, forzudo, armado, feroz, y el poeta endeble, desnudo, tímido, enamorado. Como en Barrés: Du sang, de la volupté et de la mort. Penumbra en que brillan palabras aureoladas por los recuerdos de Fray Luis y San Juan de la Cruz (cantando, la sombra, la noche... ) que son homenajes admirativos como los sabía rendir don Alfonso, en forma de guiños de ojo, uno de sus secretos poéticos. Música de grandioso órgano, con notas sombrías, pero con aquel único acorde mayor que suele iluminar las partituras de Bach. Movimiento en crescendo constante, como en Gabriel Fauré, parando a los solemnes conjuros, que continúan subiendo aún hasta el terrible grito del ábreme, en el final privilegiado del verso penúltimo. "Rómpeme el pecho y ábreme", eco, quizá, de nuestro Leconte de Lisle: "Ouvre-moi

${ }^{2}$ RoBERT ESCARPIT, "Alfonso Reyes, poète mexicain et humaniste nous parle", Une semaine dans le monde, Paris, 8 de febrero de 1947. 
la poitrine avec ton bec de fer..."'3. Poema enigmático, pesadilla misteriosa. El poeta lucha contra fuerzas profundas que conocemos muy mal, y que nos llevan a múltiples interpretaciones.

Poema de extrema violencia. Por Ifigenia cruel, como más tarde por Palinodia del polvo, entre otras páginas, ya sabíamos que el vigor realista de Reyes sabía pintar con excelencia los arrebatos furiosos, los movimientos más amplios, y hasta el cruel placer del victimario, en los suplicios más espantosos:

Os corre un vigor frío por la espalda:

Ya son las manos dos tenazas, y toda yo, como pulpo que se agarra.

$\mathrm{Y}$ en la gozosa angustia de apretar a la bestia que me aprieta, entramos en el mundo hasta pisar con todo el cuerpo el suelo.

Libro un brazo, y descargo la maza sorda de la mano. Hinco una rodilla, y chasquean debajo los quebrados huesos ${ }^{4}$.

Flota aquí, lo mismo que en "Jacob", no sabemos qué recuerdo de la antigua esfinge, que mataba a los que no resolvían el enigma... Un poema de Cocteau, de 1922, "Mort d'un cygne":

Rameurs, vous empoignez la morte...

... Tords-toi le cou, noble statue

De sel, vite retourne-toi...

... Mais à ce couteau dans mon sein...

... On devine un jeune assassin...

... Oh! venez, plongeurs ou rameurs.

A ma touchante mélodie,

N'entendez-vous pas que je meurs?...

... Car un ange qui fait la roue

Est frappé du feu du ciel.

... Nuage en croix êtes-vous Gilles...

... Bientôt je ne chanterai plus ${ }^{5}$

${ }^{3}$ LeConte DE Lisle, "Le coeur de Hialmar".

${ }^{4}$ Ifigenia cruel [1923], AROC, t. 10, p. 321.

${ }^{5}$ En Vocabulaire, Plain-chant et autres poèmes, pról. Jacques Brosse, NRF, Paris, 1983 , p. 47. 
pudo inspirar a Reyes algunos elementos de su poema: el cuchillo en el seno, el canto, el ángel-obsesión de Cocteau y, más difusos, el ambiente, el tono imperativo, el estilo directo, la vehemencia y la súplica.

En esta extraña violencia, presente con cierta frecuencia en sus escritos líricos, en aquellas despiadadas proezas de su virgenatleta, ¿encontraría don Alfonso un contrapeso, como un derivativo a su espíritu tan amigo de la mesura, en busca siempre de un equilibrio racional?

"La lucha con el ángel", tema que conoció a través de los siglos una fortuna literaria y artística excepcional ${ }^{6}$. Leyenda esotérica que figura en el libro más antiguo y familiar de la humanidad, el Génesis bíblico, en cuyo capítulo 32 se lee el relato del combate que el patriarca Jacob sostuvo durante toda la noche contra un desconocido, un "varón" invencible, protagonista diversamente interpretado pero conocido siempre como una fuerza que sobrepasa al hombre; tema intensamente comentado por los judíos, luego por los cristianos, católicos y luteranos, perteneciente a todas las épocas, desde la Antigüedad hasta los poetas más modernos, pasando por el teatro medieval, los misterios y autos españoles, todos muy presentes en el capital cultural de Reyes, sobre todo desde los tiempos de Madrid... Tema que inspiró a tantos artistas. En París, don Alfonso visitaría el famoso cuadro de Delacroix, en la iglesia Saint Sulpice: el título de su poema puede aparecer como una alusión a la presencia de aquel cuadro en nuestra capital, donde vivía entonces. Cuanto más que la gracia casi femenina del Ángel de Delacroix pudo llamar la atención de su gran amigo, el pintor mexicano Ángel Zárraga, sugiriéndole la esbeltez danzante que iba a dar a sus ángeles en sus cuadros o frescos. Pero Reyes va a reaccionar por completo contra esta versión errónea, mas tradicional, de la escena: un combate entre un ángel de elegante prerrafaelismo y un Jacob varonil. El erudito mexicano decide volver a la verdad del texto antiguo. Ya Cocteau hacía de su Ángel un "boxeador"7, y consideraba que los ángeles de la imaginería popular no eran más que "descendientes degenerados" de los ángeles antiguos, que guardaban los pa-

${ }^{6}$ Véase Robert Couffignal, La lutte avec l'ange (le récit de la genèse et sa fortune littéraire), Université Toulouse-Le Mirail, Toulouse, 1977.

7 "Les anges sont soldats, boxeurs nègres, matelots, championnes de tennis" en "Cheveux d'anges", Vocabulaire [1922], en Vocabulaire, Plain-chant et autres poèmes, p. 50 . 
lacios y eran fuertes y armados. Reyes acentúa aquel machismo, su ángel será "un gigante", le da "forzudas manos", lo dota de la potencia descomunal de un héroe de La légende. des siècles de Víctor Hugo: - "Il dit, et déracine un chêne"- capaz de romper una cabeza con un tajo de espada. La figura femenina es, al contrario, la del mismo Jacob-Alfonso. Él lucha, pero temblando, "anda confuso y temeroso", con la flaqueza tradicionalmente atribuida a las mujeres, con su miedo en la noche, su humildad y ternura. Escena erótica en su brutalidad en que Jacob se ve proveído de una psicología casi rayana en el masoquismo, aullando y a la vez cantando bajo las contorsiones del gigante que le oprime. Ya don Alfonso había expresado ciertos sentimientos suyos por la boca femenina de Ifigenia. Como Paul Claudel - antes que Claudel en su Animus y Anima-, había descrito con extraña lucidez, en "Diálogo de mi ingenio y mi conciencia", este muy humano dualismo interior, que pudiera ser uno de los sentidos del "combate con el ángel". El texto figura en El cazador, publicado en Madrid en 1921, pero data en realidad de los años de México, antes de 1913. El ingenio manifiesta un machismo brusco: "y ella se le rendía, llorando". Prefiguración de nuestro poema, página de notable penetración psicológica, con un subtítulo altamente elocuente: "Exégesis de mí mismo",

Otra tradición asiática hacía de los ángeles la transfiguración de nuestros antepasados. Algunos verán en el Ángel de Reyes la figura de su padre. "Gigante" es expresión que emplea a menudo para evocar la alta estatura física y moral del general Reyes. Con este gran soldado se relacionan la espada blandida, la idea de victoria, la ternura inmensa de su hijo, el tormento del recuerdo de su muerte trágica, que le asaltaba.

O, como en Cocteau, el ángel podía tener algo del Comendador: "Rien ne sert de prier cette vieille statue..."'.

El poema de Reyes puede ser también la evocación de lo que Cocteau llamaba "el misterio laico", el momento en que el creador quiere dar forma concreta a su sueño, escribir su obra "Sur le vide papier que sa blancheur défend", según Stéphane Mallarmé, poeta predilecto, el gran maestro de la Rue de Rome. El poeta es entonces un tirano, y somete al hombre a una dura esclavitud.

${ }^{8}$ AROC, t. 3, p. 201. En nuestro libro Alfonso Reyes et la France (1889-1959) (Klincksieck, Paris, 1978), damos la comparación precisa entre este texto de Reyes y el de Claudel, que data de 1925.

${ }^{9}$ En Plain-chant [1928], en Vocabulaire, Plain-chant et..., p. 121. 
Asistimos a este desdoblamiento, descrito por Jean Cocteau: "Imaginez une parthénogénèse, un couple formé d'un seul corps et qui accouche. Enfin, après une nuit où je pensais au suicide, l'expulsion eut lieu..."'10. Los admirables textos de Ancorajes se nos presentan para confirmarnos en esta posible explicación ${ }^{11}$. A lo largo de este precioso volumen, publicado en 1951, pero que contiene textos anteriores de diferentes épocas, se multiplican las evocaciones del "combate" del escritor, que tiene que "desenvainar" su espíritu: "en tu taller te estaban esperando, sable en mano, mil apariciones y fantasmas" (p. 25). "Hay que acudir al reto", dice. Las palabras se arman con "rejones" y lanzas, "te acribillan con sus puntas". El soberbio juego de la poesía es una “divina juglaría de cuchillos", y hasta "un ejercicio militar" (pp. 16 y 17). La misma y fuerte idea de violencia acompaña siempre estas evocaciones de las Musas. Aparece el vocablo estro, tan significativo: " . . el estro aprovecha para alancear la conciencia... [en la] metralla del polvo, [en una] herida cósmica" (p. 32). En aquella lucha trágica, "muchos han perdido [...] la vida" (p. 25). En otro texto, define la creación poética como "el asalto a ese castillo de amor que es la poesía". La perfección no se entrega de una vez. Y confiesa, empleando nuevamente la imagen del Angel en la noche:

Yo también me he quebrado alguna vez la cadera contra el Ángel de Dios, a lo largo de temerosas noches de duda y desesperanza, para amanecer el día siguiente con la sensación jubilosa de que la naturaleza toda al fin me entregaba su secreto ${ }^{12}$.

Atrevámonos a proponer una interpretación muy diferente del texto, a darle un sentido moralista, acercándolo a otro escrito capital para la comprensión de la psicología alfonsina, publicado poco antes con el título anodino de "Un propósito"13. Reyes distingue netamente en sí mismo el sello imborrable de la enseñanza positivista recibida en la Escuela Preparatoria. Le hubiera encantado vivir en el xviII francés... Entonces los artistas se dedicaban igualmente a "realidades analizadas" con el rigor cartesiachant et. .

${ }^{10}$ Cocteau, Journal d'un inconnu, citado en el pról. de Vocabulaire, Plain-

11 Tezontle, México, 1951. También en $A R O C$, t. 21.

12 Véase Agustín Basave Fernández del Valle, "La imagen del hombre en Alfonso Reyes"', Ábs, 27 (1963), p. 273.

${ }_{13}$ Publicado en Calendario [1924], en AROC, t. 2, p. 333. 
no. Poeta, don Alfonso fue siempre aficionado a las matemáticas de Einstein, a la astronomía, a la lectura de Buffon y de su descendiente Jean-Henri Fabre, entomólogo y cuentista maravilloso.

Intelectualista - aunque sin el ceño severo ni el malhumor de Julien Benda-, adhería a la corriente neo-clásica que se desarrolló especialmente en Francia a partir de la tesis famosa de Lasserre, con Jean Cocteau, Paul Valéry y sus amigos cubistas, llegados a su periodo sintético: "Algunos, aquí y allá, en todo el mundo, hemos comenzado a entendernos a guiños de ojo" ${ }^{14}$. Como ellos, enemigo del desorden y del anarquismo en todos los dominios, incluso el de la conducta y los sentimientos, denunciaba la gran corriente rival: " . . . el romanticismo, vuelto simbolismo y decadentismo primero, y al fin futurismo y dadaísmo..." que estaba desbocando en el surrealismo. La razón, dice, es nuestro "camino real": "La razón es lo mejor que tenemos los hombres".

Es difícil nuestra lucha contra el instinto y más aún contra el "abuso de sentimentalismo", severamente condenado, "chantaje, caos blanducho, cieno". Para pintar el duro combate, ya aparece el vocabulario bélico que se desarrollará en el poema: "Vamos a hacer una cruzada por lo que hay de superior en el hombre. Vamos a conquistar, a fuerza de brazo si hace falta, el respeto para las alas". Nada falta, ni las alas, a la razón disfrazada de ángel: "Hemos dado algunos en suspirar otra vez por lo que hay en nosotros que nos acerca al ángel". Nuestro canto y alegría interiores, mientras luchamos, nacen de nuestra convicción intelectual de estar en el buen camino. El triunfo final de la razón se deja entrever, luminoso como la aurora que sucede a la noche. En esta lucha consiste la libertad del hombre. Por eso, algunos años más tarde, unos clarividentes hablaron del "existencialismo" de Alfonso Reyes ${ }^{15}$.

"Jacob" puede ser también el testimonio de una de las crisis más graves que conoció Reyes, místicas o por lo menos espirituales. Recientemente, el padre Tapia Méndez emprendió el estudio de este aspecto tan rico y hasta ahora poco estudiado de la

14 Desde su tesis en la Sorbona, en 1907, vigoroso ataque contra Rousseau y el romanticismo francés, Pierre Lasserre era una figura de proa de esta corriente neo-clásica. En 1913, Reyes había asistido a sus conferencias sobre Renan; en 1930, poco tiempo antes de la muerte de Lasserre, lo recibió en Río. Véase nuestro Alfonso Reyes et la France.

${ }^{15}$ Comparando su "Estamos a bordo" con el célebre "Nous sommes embarqués" del filósofo existencialista cristiano Gabriel Marcel. Véase A. BAsave Fernández del Valle, art. cit. 
psicología alfonsina, evocando su infancia sin catecismo en una familia en que coexistían el libre pensamiento del padre y la piedad al menos oficial de la madre ${ }^{16}$. Un Cristo reinaba por encima de la cama y el obispo venía a administrar los bautismos en el comedor familiar. En México, en reacción contra el materialismo anterior, se rehabilitó casi el latín; se estudiaba la filosofía espiritualista de Bergson. En Madrid, a partir de 1914, en el Centro de Estudios Históricos dirigido por Menéndez Pidal, el joven mexicano adquirió un conocimiento profundo de la Edad Media, con su rico fondo de tradiciones y leyendas, su poesía, sus romerías, todas bañadas por la fe cristiana. Publicó una bella traducción de Ortodoxia de Chesterton, prueba de su interés por estos problemas. Además, había ganado la fraternal amistad de Enrique Díez-Canedo, de ideas liberales, pero hijo de una familia de gran tradición religiosa. Sin frecuentar asiduamente la iglesia, Enrique era partidario de un cristianismo progresista, apasionado admirador y comentarista de León Bloy ${ }^{17}$. Hubo los paseos y las íntimas pláticas con Amado Nervo. Después de la muerte de este último, Alfonso se dedicó a reunir su obra monumental, que toda desbocaba en una incertidumbre serena de la religión, investigaciones que exigieron del editor una leal actitud de comprensión y respeto. Simpatía tan eficaz que a veces no sabemos si Alfonso habla de su amigo o confiesa sus propias dudas: "La sinceridad de su sentimiento religioso resiste la prueba superior: la de la humillación ante la cólera divina. Mientras no se ha sentido sino el amor de Dios, se es un místico muy confortable"'18. Nos enfrentamos otra vez con el drama de nuestro poema; y más aún con los versos de Nervo que Reyes cita a continuación, con tal que se acepte la confusión - frecuente- entre el Ángel y San Miguel:

¡Oh, Señor, no te enojes con la brizna de yerba!

Mi nada no merece la indignación acerba de un Dios... ¿Es ley que emplees la flamígera espada de tu resplandeciente Miguel contra mi nada?

${ }^{16}$ Aureliano Tapia Méndez, Alfonso Reyes ante Dios y ante la muerte, Instituto de la Cultura de Nuevo León, Monterrey, 1989.

${ }^{17}$ Cf. nuestra ponencia "Amistosa tríada: Valery Larbaud, Enrique Díez-Canedo, Alfonso Reyes", en el X Congreso de la Asociación Internacional de Hispanistas, Barcelona, 1989 (actas en prensa).

18 Véanse bajo el título "Tránsito de Amado Nervo", los textos que Reyes publicó en 1914, 1919, 1929, en $A R O C$, t. 8, pp. 11-49. Cita, p. 17. 
Conviene entonces colocar a "Jacob" en su circunstancia, imaginar el cuadro y el momento en que vivía don Alfonso cuando lo escribió, en el nublado París, y en 1925. Contrariamente a España, tierra de acogida calurosa, la capital francesa siempre le había inspirado cierto sinsabor de soledad, a pesar de todos sus encantos y de buenos amigos, "aunque amando entrañablemente a Francia". Aislamiento, simbolizado aquí por la noche, imagen ya latente en el texto bíblico: "Y se levantó aquella noche. . A Así se quedó Jacob solo...". En el silencio nocturno, se borran las fronteras entre el sueño y la realidad. Cerrados a los ruidos del mundo, podemos contemplar más fácilmente nuestro misterio interior, "cada hombre tiene que enfrentarse con su propia noche". El poeta, o el místico, se abren a la potencia oculta que impregna el universo, a la que algunos llaman Dios. Cocteau, en Le secret professionnel, habla de "la locura del poeta". Locura o clarividencia: los demás no se atreven, por miedo o inconciencia, a entrever así esta abertura a otro mundo.

Esta intensa reflexión sobre sí mismo, Reyes la traduce acumulando verbos personales, enumerando posesivos (mis costados, mis flancos, mi sangre), insistencia poco conforme al uso español. Nótese la abundancia de los pronombres: derrótame, rómpeme, ábre$m e$. En esta soledad, "la mort lui fait les yeux doux". Obsesión de la muerte que no deja al autor de El suicida desde el drama paterno, idea hecha más presente todavía por la sangre de los años de Revolución en México, por los millones de cadáveres de la guerra europea, acontecimientos todos vividos intensamente desde Madrid; por su mala salud en Madrid (tifoidea grave) y en París ("tiemblo por mi salud") 19. "Pense à mon rendez-vous", repite la muerte al poeta francés. Entonces, el Ángel, ¿la misma muerte?

El ministro de México en Francia tenía entonces 34 años. A esta edad, Cocteau escribía: 'La jeunesse me quitte et j'ai son coup reçu" ${ }^{20}$. Después de ser niño y escritor precoz, el ministro más joven de París veía, con las responsabilidades enormes que le incumbían con el fin de introducir otra vez a su país en el concierto de las naciones, acercarse a él una prematura madurez. Estos momentos de transición entre una y otra etapa de la vida se sue-

${ }^{19}$ Reyes, Diario (1911-1930), Universidad de Guanajuato, Guanajuato, 1969 , p. 116.

${ }^{20}$ Cocteau, "L'endroit et l'envers", en Vocabulaire, Plain-chant..., p. 100. 
len vivir con melancolía... Así se explica aquella impresionante "Carta a dos amigos", que Reyes escribió muy poco tiempo después de nuestro poema, en enero de 1926, dirigida a Enrique DíezCanedo y Genaro Estrada, pero publicada en Addenda a Reloj de sol sólo en 1956, cuando reunió sus Simpatías y diferencias en el tomo 4 de sus Obras completas, como un testimonio histórico de sus inquietudes en aquellos tiempos de Europa. Ya le preocupaba en 1926 el destino de su obra literaria. Pero el texto no es sólo testamento de escritor, contiene al final una frase de las más importantes, que lanza una luz viva en esos años de París en que "Dios estaba a la vista": "Una inquietud —-desoída siempre- está golpeando con insistencia a mis puertas. Amigos: apenas es tiempo. Que empiece yo firmemente a creer en Dios, y todo habrá cambiado, todo" "21. Infiérese fácilmente que estos dos amigos ya recibirían confidencia de esta "tentación de Dios", hipótesis confirmada por una carta a Díez-Canedo, inédita, eco de otra crisis semejante que don Alfonso atravesó en Río, el 6 de agosto de 1931: “... ¿Qué vendrá después? Pascal es muy fácil. Él dice: ¡Arrodíllate! Pero yo no puedo, no me resulta sincero. ¿Qué haré, Enrique...? escríbame un poco. A veces siento que todo se cierra y me deja fuera"'22. Es posible que el epistolario Alfonso Reyes-Genaro Estrada, todavía por publicar, nos dé otras pruebas de tan íntima amistad.

La coyuntura literaria francesa favorecía en 1925 este impulso hacia lo sagrado. Desde varios años, era Reyes gran admirador del poeta católico Paul Claudel, su modelo en poesía y diplomacia. Valery Larbaud había abjurado el severo protestantismo de su infancia para recibir el bautismo de Roma. En París, Jacques Maritain reinterpretaba al tomismo, con nueva síntesis de la fe y la razón, intento muy atractivo para Reyes, siempre racionalista. El mismo Jean Cocteau reanuda el catolicismo de su infancia, en un sentido más activo, y obtiene el bautismo de varios amigos suyos. Parece que Reyes, en sus años de París, no conoció personalmente a Jacques Maritain, pero indudablemente leía sus escritos. Poco tiempo después, en el momento de fundar una revista con sus :jóvenes amigos de Buenos Aires, intentó inspirarse en su Roseau d'or ${ }^{23}$. El peruano Francisco García Calderón,

21 "Carta a dos amigos", en $A R O C$, t. 4, p. 482.

${ }^{22}$ Carta de Alfonso Reyes a Enrique Díez-Canedo, Capilla Alfonsina de México.

${ }^{23}$ Véase su carta a Valery Larbaud, del 7 de mayo de 1929, en nuestra 
muy amigo de Reyes y ya su prologuista en 1910, le relacionaba con el grupo de Maritain y Henry Massis. Atraído por este clima de renacimiento del catolicismo, Reyes era sin embargo el representante en París de un gobierno que aplicaba en México la política anticlerical más dura. Sin duda era don Alfonso un partidario resuelto de la separación de la Iglesia y del Estado. Mas, siempre y por todas partes, fue hombre de tolerancia, un conciliador. Así se entienden mejor unas notas firmadas de la mano de nuestro gran Aristide Briand, conservadas en los archivos del Ministerio de Relaciones Exteriores del Quai d'Orsay, las cuales relatan el desconcierto y hasta las lágrimas de Reyes durante sus visitas a nuestro Ministro ${ }^{24}$.

Otra vez, volvamos al texto. Algunas palabras revelan bien una cierta cristianización, entre las líneas, del mito de Jacob, cierta identificación del poeta-víctima con Cristo. A Cocteau, también, en su poema La Crucifixión, le duelen los golpes recibidos por Cristo: es propio de los místicos llegar a vivir el suplicio de Jesús. El muslo descoyuntado de Jacob, el tendón tocado por el varón de la Biblia, en Reyes, vienen a ser los flancos, el pecho, donde fue herido el Señor; "mi sangre" es la reproducción de las divinas palabras de la Cena, interpretación apoyada por el empleo extraño, guiño de ajo revelador, de consunción, que no es sólo vocablo del vocabulario médico, sino también término teológico: la consunción de las especies, destrucción de la sustancia del pan y del vino. Notemos hasta qué punto del conocimiento religioso y místico le habían llevado a Reyes sus lecturas de san Agustín, santo Tomás, santa Teresa, san Juan de la Cruz, sor Juana, entre otros muchos, además de los textos sagrados, su lectura constante.

Lejos de nosotros la idea de forzar el secreto de las almas. ¿Fue Reyes "un cristiano secreto", como unos lo pretendieron? A veces en México cundió el rumor de su conversión. Mas nos limitaremos a enunciar lo que escribió. Por lo visto, la crisis de 1925 no le permitió afirmar su fe naciente, ya que atravesó al menos otra semejante en Río, en 1931. ¿Le faltaría "esta curvatura del alma... la llama de religión comunicada en la infancia" 25 . Pero lo mismo pasó a Cocteau, a pesar de su educación religiosa.

edición de Valery Larbaud-Alfonso Reyes, Correspondance 1923-1952, Didier, Paris, 1972, p. 58.

24 Véase nuestro Alfonso Reyes et la France.

${ }^{25}$ La envidiaba en Amado Nervo; cf. "Tránsito de Amado Nervo", en $A R O C$, t. 8, p. 22. Texto escrito en 1919. 
Parece que los intentos de don Alfonso para acercarse a Dios se hicieron todos en el dolor y la violencia. No concebía una religión "tierna e insípida", prefería "el sobresalto sagrado": "Nada de religión soñolienta. La vida es terrible ... ¿La serenidad? ¡Oh sí! Pero no la serenidad a priori. La serenidad es corona de las pasiones"'26.

Llegó a conocer a Maritain en Buenos Aires, en 1936. No sabemos casi nada de sủ encuentro, quizá evocado en el Diario de Reyes (1930-1959), monumento todavía desconocido y tan deseado. Él seguía leyendo los escritos del pensador francés, especialmente en Ábside, la revista de sus buenos amigos, los eruditos sacerdotes Alfonso y Gabriel Méndez Planearte. Observaba las cualidades y los límites de Jacques Maritain... ${ }^{27}$.

El mito del ángel reapareció de vez en cuando en sus páginas, siempre batallador, cada vez enriquecido. Continuaba cierto parentesco entre la obra alfonsina y la de Jean Cocteau, al cual entendió mejor y antes que todos. Sólo ahora, destacado de las "leyendas ridículas" en que se dejaba envolver $-o$ en que se escondía-, nos aparece Jean Cocteau como un creador de nuestra cultura moderna, en la que continúa la corriente clásica.

En los muchos años que dedicó Alfonso Reyes a sus estudios helenísticos, se produjo en su mente una como síntesis entre la filosofía antigua y el cristianismo. El catolicismo podía ser "la última conquista de la cultura clásica". Se dejó seducir por la Siria de los tiempos evangélicos: era país "todavía helenizado... que no había sufrido el influjo oriental de los musulmanes" 28 . Dio toda su importancia al neoplatonismo de Plotino, a quien colocaba, con muchos, por encima de Platón y Aristóteles. Plotino era autor de "imperecederas páginas sobre la belleza ...", había tendido el deseado puente "entre la filosofía helénica y la filosofía cristiana". Era místico sin ser cristiano. En Reyes se hizo cierta identificación entre la posición de Plotino y sus propias experiencias:

26 "Carta a Alfonso Junco", Reloj de sol, en $A R O C$, t. 4, p. 417. Texto escrito en Madrid en 1920. La gran amistad de Reyes por el poeta católico Alfonso Junco, y la comprensión delicada que tuvo de su obra, merecerían un estudio aparte.

${ }^{27}$ Reyes reprochaba a Maritain su escaso conocimiento de los escritores religiosos españoles.

${ }^{28}$ Véase el buen estudio de esta síntesis en el libro del padre Tapia Méndez, ya citado. 
Sin duda que la sola operación racional no le parecía suficiente para llegar a Dios, pero sí la consideraba como una preparación indispensable. Tras el lúcido análisis de la inteligencia, sólo quedaba abrir la ventana y esperar la Visitación ${ }^{29}$

. . la Visitación, es decir, aquí, la venida del Ángel.

En su contestación a Robert Escarpit, efectivamente, Reyes tenía razón. No era sólo un humanista. Era ante todo un poeta, un gran poeta sincero y sensible, cuya maestría supo darnos, con "Jacob", una de las versiones más bellas de la bíblica lucha con el ángel, inolvidable recuerdo de una noche de violento trastorno y amor, en el París de 1925.

Paulette Patout

Universidad de Toulouse 